\title{
Globe
}

Revue internationale d'études québécoises

Michel Ducharme, Le concept de liberté au Canada à l'époque

des révolutions atlantiques 1776-1838, Montréal, McGill-Queen's University Press, 2010

\section{Bernard Andrès}

Volume 14, numéro 1, 2011

URI : https://id.erudit.org/iderudit/1005997ar

DOI : https://doi.org/10.7202/1005997ar

Aller au sommaire du numéro

Éditeur(s)

Globe, Revue internationale d'études québécoises

ISSN

1481-5869 (imprimé)

1923-8231 (numérique)

Découvrir la revue

Citer ce compte rendu

Andrès, B. (2011). Compte rendu de [Michel Ducharme, Le concept de liberté au Canada à l'époque des révolutions atlantiques 1776-1838, Montréal,

McGill-Queen's University Press, 2010]. Globe, 14(1), 226-228.

https://doi.org/10.7202/1005997ar d'utilisation que vous pouvez consulter en ligne.

https://apropos.erudit.org/fr/usagers/politique-dutilisation/ 


\section{Michel Ducharme}

Le concept de liberté au Canada à l'époque

des révolutions atlantiques 1776-1838,

Montréal, McGill-Queen’s University Press, 2010.

Issu d'une thèse de doctorat soutenue à l'Université McGill, ce livre procède à une relecture de la genèse de l'État canadien entre la Révolution américaine et les rébellions de 1837-1838. En analysant le concept de liberté dans le discours politique à l'époque des révolutions atlantiques, Michel Ducharme fait dialoguer les traditions historiographiques liées, dit-il, à nos deux «solitudes » : la canadienne-anglaise et la québécoise. Il s'agit pour lui de «dépasser le manichéisme traditionnel voulant que les colons britanniques aient, en refusant la révolution, nécessairement refusé la liberté et les idées des Lumières» (p. 7). Loin de considérer comme contrerévolutionnaire le refus des British settlers de suivre l'exemple américain dans les années 1770-1780, Michel Ducharme argue que les colons anglais du Canada ont opté pour une autre forme de liberté. Cette dernière, qualifiée de «moderne», repose sur la constitution de 1791 qui accorde enfin aux coloniaux une forme de représentation. À l'autre extrémité du spectre idéologique figure alors la liberté républicaine. Elle s'inspire des révolutions française et américaine et suppose, chez les Patriotes bas et haut-canadiens, une reconfiguration drastique des pouvoirs coloniaux.

Pour mener à bien son étude "plus intellectuelle qu'institutionnelle", avertit Ducharme (p. 11), on procède à une analyse interne des discours politiques diffusés durant cette période. L'auteur s'intéresse au principe même de la liberté comme fondement de la légitimité de l'État, plutôt qu'à tels ou tels type de liberté ou de droits observables dans les colonies (habeas corpus, liberté de parole, de religion, d'association, etc.). L'analyse repose sur le large corpus des documents publics circulant alors tant en métropole qu'au Canada (textes légaux et constitutionnels, résolutions, pétitions, adresses, correspondances officielles, imprimés, etc.). Ducharme rappelle comment, de Thomas Hobbes à Jean-Louis De Lolme, de Montesquieu à Jean-Jacques Rousseau, Madame de Staël et Benjamin Constant, deux types de liberté cohabitent ou s'affrontent: celle de l'individu et celle du corps social. L'auteur fait fond sur l'opposition de Constant entre "liberté des Anciens" (assujettissement de l'individu au groupe) et "liberté des Modernes" (autonomie du sujet jouissant de ses droits individuels) pour caractériser la «liberté moderne» défendue au Canada par les autorités coloniales et leurs 
partisans. Ces derniers sont désignés par le terme "constitutionnels", car, jusque dans la crise des années 1830 qui conduira aux rébellions, ils ne dérogeront jamais à la constitution de 1791, reprochant aux "républicains» de remettre en cause les principes mêmes de l'État et du droit anglais.

À la liberté "moderne" (droits naturels inaliénables de la naissance, donc de l'inégalité sociale, droits de la propriété privée et de la sécurité, assurés par la constitution britannique), s’oppose la liberté républicaine (égalité des citoyens réunis dans un peuple indivisible et univoque, réduction des écarts de fortune en vue du bien commun, etc.). C'est ce clivage entre les deux libertés, explique Ducharme, qui anime les débats parlementaires canadiens jusqu'à l'impasse et aux rébellions de 1837-1838. En bloquant progressivement le fonctionnement du Parlement, le Parti canadien, puis les Patriotes provoquent l'ire des constitutionnels persuadés, eux, que la souveraineté du peuple menacerait les libertés individuelles, la sécurité comme la prospérité coloniales. À la souveraineté populaire s'exprimant dans le pouvoir législatif répond chez les constitutionnels un exécutif garant des libertés individuelles dans un cadre parlementaire mixte où s'équilibrent monarchie, aristocratie et démocratie.

En suivant pas à pas les débats et polémiques alimentés au BasCanada comme dans le Haut-Canada par les révolutions américaine et française, mais aussi par la pensée politique des Lumières, Ducharme reconstitue brillamment la genèse et les aléas du concept de liberté en Amérique du Nord. Cette réflexion redonne tout son poids à l'Acte constitutionnel de 1791 et à la façon dont les réformistes canadiens ont basculé dans les années 1820 d'une conception à l'autre de la liberté. Plus axée sur les aspects idéologiques qu'économiques de la crise, l'analyse conduit à une relecture des années 1830 et de l'impasse qui s'en suivit. Incapables de compromis avec les "constitutionnels" (eux-mêmes rivés sur leur idée de la liberté), patriotes francophones et radicaux anglophones des deux Canada ne peuvent que verser dans l'affrontement extra-parlementaire.

S'il montre bien qu'alors le clivage est moins ethnique qu' intellectuel et politique, l'auteur observe toutefois que, dans l'esprit des constitutionnels fidèles à l'Angleterre, les Bas-Canadiens restent stigmatisés par leurs origines françaises, comme les Haut-Canadiens le sont par leur provenance américaine. "Pour les constitutionnels, les républicains sont des étrangers: Canadiens français au Bas-Canada, Américains ou admirateurs des États-Unis au Haut-Canada", note l'auteur (p. 220). Pis encore en ce qui concerne les francophones. Les préjugés ethniques à leur endroit pullulent dans les écrits gouvernementaux: avec leurs goûts simples et leur prédilection 
pour l'agriculture de subsistance et non pour le commerce, par leur résistance au "progrès ", les Bas-Canadiens nuisent à la prospérité coloniale dans son ensemble: "The anti-commercial proceedings of the French faction [...] have driven the inhabitants of Upper Canada to contemplate a scheme, which, if successful, must be fatal to "the commercial classes" of Lower Canada", écrit en 1836 Adam Thom dans ses Anti-Gallic Letters, rapporte Ducharme (p. 200).

On le voit, bien que toute son analyse établisse avec soin l'importance de cette opposition entre deux conceptions de la liberté, l'auteur ne peut que signaler au passage le caractère "ethnique» (dirais-je raciste?) des positions constitutionnalistes. Le lecteur constate alors qu'au-delà des beaux principes philosophico-politiques débattus à l'époque, la victoire du concept moderne de liberté conduit à la répression, à la suspension de la fameuse constitution, au Conseil spécial... et au sort que réservera l'Union aux Canadiens français. Mais, il est vrai, ceci excède la période couverte par l'auteur. Du reste, Ducharme atténue considérablement dans sa conclusion les effets (ou les méfaits) du Conseil spécial qui, affirme-t-il, respecte «les principes de la liberté moderne" en assurant "la sécurité des personnes et de l'État à la suite des rébellions", ainsi, notamment, que «le dragage du lac Saint-Pierre (1838), la construction du canal de Chambly (1840) et l'établissement de bureaux d'enregistrement (1841)» (p. 233-234)!

Un nouvel ordre est né, conclut sereinement l'auteur, «fondé sur les principes de liberté, d'égalité et de propriété. C'est cet ordre qui est à la base de l'État canadien modèle» (p. 237). On comprend ici l'avertissement de l'auteur qui, dans son introduction, $s$ 'inscrit avec Jocelyn Létourneau dans ce mouvement de "révision du cadre national et nationaliste», soucieux de "dépasser le cadre national québécois et de réintégrer l'histoire du Québec dans le cadre canadien» (p. 9).

Bernard Andrès

Université du Québec à Montréal

\section{Lee Skallerup (dir.) \\ Anne Hébert. Essays on Her Works, \\ Toronto, Guernica, 2010.}

Dirigé par Lee Skallerup, spécialiste de littérature comparée, et plus particulièrement de l'œuvre poétique d'Anne Hébert, à laquelle elle a 